\title{
Managing type 1 diabetes in the active population
}

\author{
Nicola Keay 이, ${ }^{1}$ Richard M Bracken ${ }^{2}$
}

'Department of Sport and Exercise Sciences, Durham University, Durham, UK ${ }^{2}$ Applied Sport, Technology, Exercise and Medicine Research Centre (A-STEM), Swansea University, Swansea, UK

\section{Correspondence to}

Dr Nicola Keay, Department of Sport and Exercise Sciences, 42 Old Elvet, Durham, DH1 3HN, Durham University, Durham, DH1 3HN, UK; nickykeayfrancis@googlemail. com

Accepted 4 November 2019

\section{Check for updates}

(c) Author(s) (or their employer(s)) 2019. No commercial re-use. See rights and permissions. Published by BMJ.

To cite: Keay N, Bracken RM. Br J Sports Med Epub ahead of print: [please include Day Month Year]. doi:10.1136/ bjsports-2019-101368

\section{BACKGROUND}

Many high-profile athletes participate across a wide range of sports with type 1 diabetes. Team Type 1 encourages and supports those with type 1 diabetes to participate in physical activity, with professional cycling's Team Novo Nordisk composed entirely of individuals with type 1 diabetes. Type 1 diabetes is likely to present early in an athlete's career, a time when athletes may present with fatigue due to increased training loads. All physicians need to distinguish between possible causes of fatigue in these athletes.

Type 1 diabetes is an autoimmune condition with T-cell-mediated destruction of the pancreatic $\beta$ cells of the islets of Langerhans, resulting in failure to produce sufficient insulin. The clinical outcome is an inability to adequately control glucose metabolism. Effective glucose metabolism is crucial in long-duration and high-intensity exercise. Selfadministered exogenous insulin is required as a treatment to manage blood glucose.

The physiological response to exercise is a progressive decrease in insulin and increase in the pancreatic $\alpha$-cell-derived antagonist hormone glucagon, while exercise also increases insulin sensitivity (increased 'sensitivity' means that for a given dose, there is a more pronounced effectinsulin does its job 'better'). In addition, there is an exercise-induced rise in sympathoadrenal hormones (epinephrine and norepinephrine). This hormonal response influences circulating glucose and fat use, and is usually well-regulated. This is not the case in athletes with type 1 diabetes, where there is a substantial risk of both hyperglycaemia and hypoglycaemia. Patients often have the low bottom of range blood glucose for many hours after exercise. ${ }^{1}$ Individual with type 1 diabetes often need 48 hours to reset their autonomic function and replenish glycogen stores. ${ }^{2}$

\section{CASE: ROWER WITH A BIG THIRST, WEIGHT LOSS AND FATIGUE}

An 18-year-old first-year university rower noticed that during an off-site training camp he was drinking a lot of water and losing weight, which he put down to maladaptation to the high training load in a hot climate. However, symptoms worsened when he returned to campus after the training camp. $\mathrm{He}$ reported feeling extremely fatigued, weak and sick, and was admitted to hospital. Following a formal diagnosis of type 1 diabetes, he reported receiving very little advice on discharge-what was offered was very generalised and there was no follow-up appointment offered. So he researched how to manage diabetes while exercising and looking for recommendations specific to rowing. He reported that information gave him the confidence to try to manage the condition and continue with his chosen sports.

\section{CLINICAL QUESTIONS}

- How can clinicians raise awareness of type 1 diabetes as a possible cause of fatigue in active individuals and hence identify these athletes?

- How can we educate athletes with sportsspecific information and support?

\section{CLINICAL FEATURES \\ History}

Athletes may present with fatigue, polydipsia, polyuria and weight loss. There may be recent episodes of infective illness. Athletes may also present initially with acute signs and symptoms consistent with diabetic ketoacidosis.

\section{Examination}

Examination should be relevant to the athlete's presenting complaint. If there is a high clinical suspicion of type 1 diabetes, then examine for any vitiligo that may indicate an autoimmune disease. Funduscopy/retinal photography can also be considered at this stage.

\section{Diagnostic tests}

These should include routine bloods tests (full blood count, renal profile, blood glucose, liver function and thyroid function) and glycosylated haemoglobin (HbA1c). Oral glucose tolerance test may be considered. Testing for $\beta$ cell antibodies may be considered in those aged $<45$ years at diagnosis.

According to the WHO diagnostic criteria 2010, confirmation of diabetes mellitus diagnosis in a person with hyperglycaemic symptoms is with random/postprandial blood glucose $\geq 11.1 \mathrm{mmol} / \mathrm{L}$ $(200 \mathrm{mg} / \mathrm{dL})$, or fasting blood glucose $\geq 7.0 \mathrm{mmol} / \mathrm{L}$ $(126 \mathrm{mg} / \mathrm{dL}){ }^{3}$

\section{MANAGEMENT}

The aim is to mimic the natural physiological response of glucose metabolism to exercise. ${ }^{3}$ Figure 1 summarises the key principles of management. Management is subject to a number of considerations:

- Insulin sensitivity: 0.5 unit $/ \mathrm{kg}$ is required to reduce blood glucose by $4 \mathrm{mmol} / \mathrm{L}$.

- Insulin should be injected into the nonexercising muscle, as hyperaemia will be present in exercising muscle.

- Peak insulin bolus occurs 60-80 min post injection, with peak reduction of blood glucose occurring 90-120 min postinjection. 


\section{Management of Diabetes in Athletes}

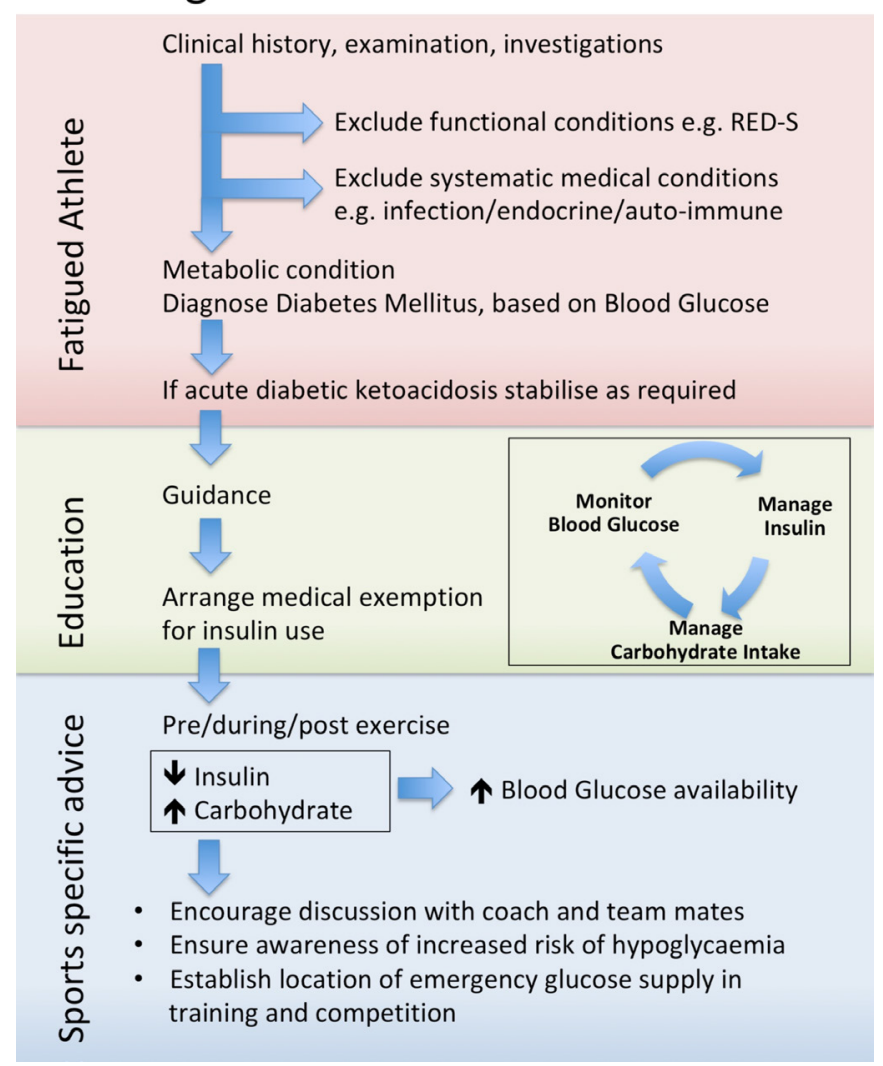

Figure 1 Management of diabetes in athletes.

The objective is to manage insulin levels while athletes are training/racing. To achieve this, strategies revolve around injecting a lower dose of insulin and/or more carbohydrate intake, including ${ }^{45}$ :

- Reducing bolus insulin before exercise.

- Ensuring carbohydrate intake during exercise.

- Replenishing glycogen stores postexercise with a range of options: a carbohydrate-rich and protein-rich meal intake, reduction of bolus insulin with the next meal and reduction of basal evening insulin to avoid overnight hypoglycaemia.

\section{ONGOING CARE}

Soon after an athlete is diagnosed with type 1 diabetes, there can be a 'honeymoon period' when exogenous insulin requirements are not high, due to residual $\beta$ cell function: athletes should be alerted to the importance of monitoring blood glucose and modifying insulin doses appropriately. Dietary advice should be offered by an appropriately qualified dietician; this will include guidance on daily intake, in particular, carbohydrate and timing of intake around exercise training and competition. ${ }^{6}$

Insulin is on the banned WADA list both in and out of competition, so athletes with type 1 diabetes require therapeutic medical exemption. $^{7}$

\section{PRACTICAL TIPS}

- Always consider the possibility of type 1 diabetes mellitus in athletes presenting with fatigue.

- Provide adequate generic and sports-specific education.

- Empower and support athlete to make personalised changes to optimise their glucose management.

- Encourage support from teammates and coaches. Identify the location of the emergency source of glucose during training/competition.

- Mentorship of athletes from fellow athletes with type 1 diabetes can be beneficial.

\section{Twitter Nicola Keay @nickykfitness}

Collaborators Amber Medley, Executive Director of the Team Type 1 Foundation, and Jake Lane, Durham University.

Contributors NK was commissioned by a Senior Associate Editor BJSM to write this educational article. NK invited RNB, AM and JL to contribute and comment on the initial draft written by NK.

Funding The authors have not declared a specific grant for this research from any funding agency in the public, commercial or not-for-profit sectors.

Competing interests None declared.

Patient consent for publication Not required.

Provenance and peer review Commissioned; externally peer reviewed.

ORCID iD

Nicola Keay http://orcid.org/0000-0001-6663-7010

\section{REFERENCES}

1 Colberg SR, Sigal RJ, Yardley JE, et al. Physical Activity/Exercise and diabetes: a position statement of the American diabetes association. Diabetes Care 2016;39:2065-79.

2 Riddell MC, Gallen IW, Smart CE, et al. Exercise management in type 1 diabetes: a consensus statement. Lancet Diabetes Endocrinol 2017;5:377-90.

3 Sigal RJ, Armstrong MJ, Bacon SL, et al. Physical activity and diabetes. Can J Diabetes 2018;42 Suppl 1:S54-63.

4 Runsweet. Managing diabetes with sport, why is there any problem? Available: http:// www.runsweet.com/diabetes-and-sport/ [Accessed 01 Jun 2019].

5 Gallen I. Type 1 diabetes: clinical management of the athlete. Springer, 2012.

6 Adolfsson P, Riddell M, Taplin C, et al. International Society for adolescent and paediatric diabetes (ISPAD) clinical practice consensus guidelines: exercise in children and adolescents with diabetes. Pediatric Diabetes 2018;19:205-26.

7 The world anti-doping code international standard 2019. 